case report

\title{
Lateral ventricle epidermoid
}

\author{
Artur Franko, Izidora Holjar-Erlić, Damir Miletić \\ Department of Radiology, Clinical Hospital Rijeka, Croatia
}

\begin{abstract}
Background. Epidermoids occurring within the lateral ventricles are rare. They are slow growing benign tumours, usually presented with non-specific signs of deterioration of mental functions.

Case report. Authors present a case of 49-year-old woman with epidermoid located in the frontal part of lateral ventricle. She underwent magnetic resonance imaging before the surgical treatment and the final patohistological diagnosis.
\end{abstract}

Conclusions. Suprasellar and intraventricular epidermoids are rare, but must be included in differential diagnoses as well as meningeomas, ependimomas, subependimomas and papillomas of the choroid plexus.

Key words: epidermoid; intraventricular; arteriovenous malformation (AVM)

\section{Introduction}

Epidermoid tumours represent $0.2 \%$ to $1 \%$ of all primary intracranial tumours. ${ }^{1}$

Intracranial epidermoid tumours are histologically benign, slow-growing, congenital neoplasms of the central nervous system. $^{2}$ They usually present in adults and are commonest in the cerebellopontine angle or suprasellar region protruding in the subarahnoid space. ${ }^{3}$ Epidermoids occurring within the lateral ventricles are very rare. They are slow growing, and the clinical presentation is non-specific like deterioration of mental functions. ${ }^{4}$

To our knowledge, there were only 7 reports of epidermoids located in lateral ventricles. ${ }^{2,4-6}$ We report a case of bulky lateral

Received 7 January 2008

Accepted 21 January 2008

Correspondence to: Izidora Holjar-Erlić, MD, Department of Radiology, Clinical Hospital Rijeka, Krešimirova 42, 51000 Rijeka, Croatia; Phone/Fax: +385 51651 386; E-mail: izidora.holjar@ri.htnet.hr ventricle epidermoid with mass effect on adjacent structures.

\section{Case report}

A 49-year-old woman was admitted to the Clinic of Neurology due to progressive mnestic deterioration, mild headache and right limbs parestesia. The neurologist found discrete right limb paresis, disorientation and psychomotor deceleration. The score of mini-mental test was low $(17 / 30)$ and after testing the psychologist concluded that her dysfunctions had an organic cause. The neurologist suspected on the brain tumour but also on the progressive demyelinating disorder and sent the patient directly to the magnetic resonance imaging (MRI) of the brain without previous computed tomography (CT).

Within the frontal part of the left lateral ventricle on T1-weighted images a large formation with heterogeneous signal and 


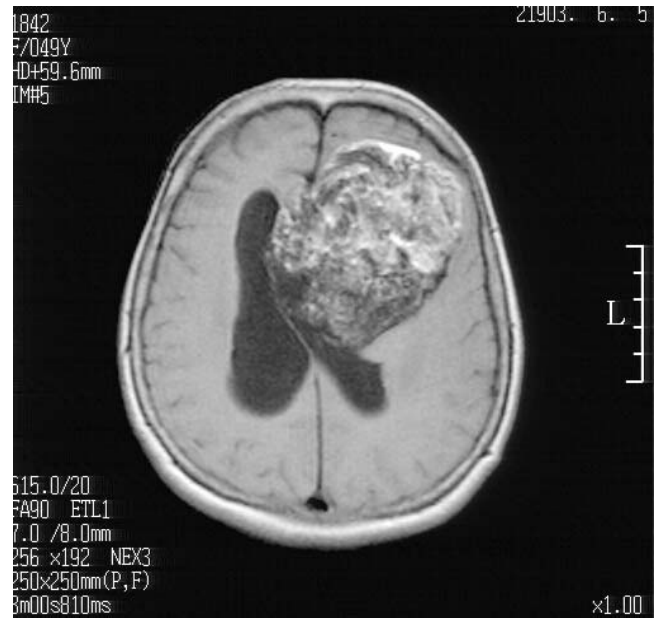

Figure 1. Axial T1-weighted MRI scan reveals a large, bulky mass within the left lateral ventricle containing high-signal areas and low-signal foci.

significant hyperintense areas was obtained (Figure 1). After the contrast administration MRI showed a loose heterogeneous enhancement and sharp, well defined margins. This lesion had a spatiocompresive effect on surrounding structures, especially on foramen of Monro resulting with unilateral obstructive hydrocephalus (Figure 2).

The patient was restless during the MRI examination and T2-weighted sequences were undiagnostic. On FLAIR-weighted scans the MRI signal of the lesion was very similar to T1-weighted images. High signal areas were interpreted as subacute haemorrhage or fat inclusions (Figure 3).

The expansive neoplastic formation was interpreted as benign and the differential diagnosis was focused on central intraventricular menigeoma, central neurocytoma, and subependymal giant cell astrocytoma.

The patient was transported to neurosurgery and underwent frontal craniotomy with a complete removal of brain tumour. Patohistology confirmed the benign intraventricular tumour - epidermoid.

The control MRI was performed six months after the surgery revealing no recurrence.

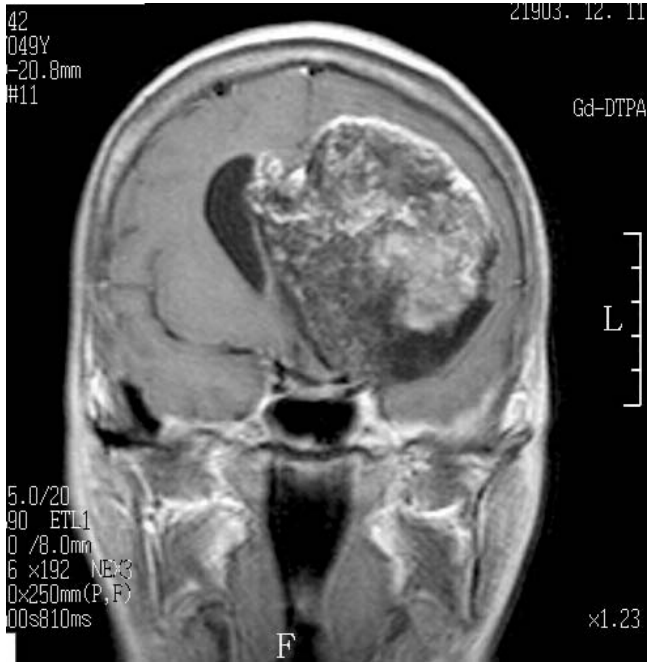

Figure 2. Postgadolinium coronal section shows very discrete heterogeneous enhancement and huge mass-effect on adjacent structures including septum pellucidum and foramen of Monro.

\section{Discussion}

Tumours are only rarely found in the lateral ventricles. ${ }^{7}$ Although they are relatively easy to visualize, it is more difficult to narrow the differential diagnosis for a lesion in this location without knowledge of the tissue types that give rise to these tumours. ${ }^{8}$ Epidermoid tumours are the most common fourth ventricular low density lesions and represent $5-10 \%$ of all intracranial epidermoids. ${ }^{9}$ The location in the lateral ventricle, especially in the frontal horn, is very rare and that was the reason why authors initially did not think on it as a differential diagnosis.

The MRI usually demonstrated an irregularly but sharply demarcated mass with inhomogeneous density, variable enhancement with gadolinium, lack of invasion to adjacent normal structures, and extensive protrusion into cisternal and other cerebrospinal fluid with high-signal intensity on proton-weighted images. ${ }^{10}$ In our case the lesion was inhomogeneous before and after the contrast administration with foci of 


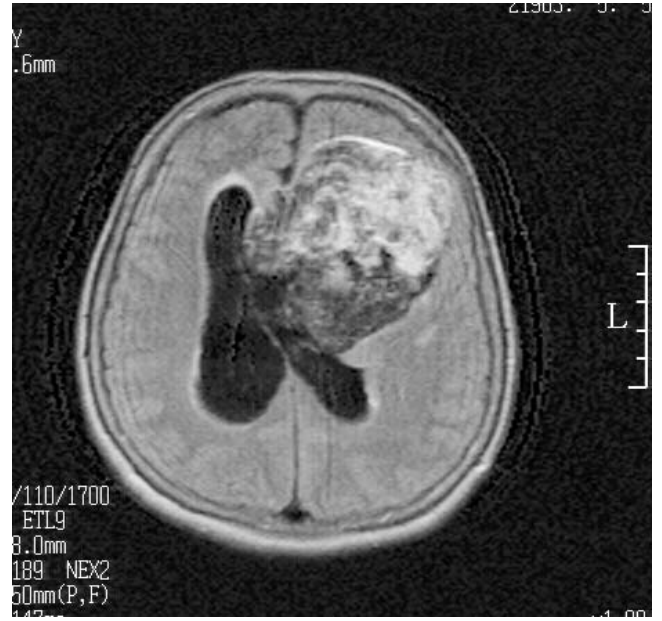

Figure 3. Despite significant movement artifacts FLAIR-weighted MRI shows hiperintense areas mostly corresponding to the same areas on T1-weigthed image.

contrast enhancement. The patients would benefit if MRI spectroscopy would be done, but this was impossible due to patient's restlessness.

In histopathological specimens bone metaplasia and abundant lipoid detritus were found explaining signal heterogeneity. High-signal inclusions corresponded to fat. Because of the lack of mobile hydrogen, deposits of calcium appear on MR images as foci of diminished signal intensity within the tissue harbouring them. In our case CT was not performed and calcifications were missed.

Despite all imaging techniques the histopatological diagnosis was indispensable.

\section{References}

1. Sener RN, Mechl M, Prokes B, Valek VA. Epidermoid tumor of the pons. J Neuroradiol 2004; 31: 225-6.

2. Akar Z, Tanriover N, Tuzgen S, Kafadar AM, Kuday C. Surgical treatment of intracranial epidermoid tumors. Neurol Med Chir 2003; 43: 275-81.

3. Sutton D, Stevens J, Miszkiel K. Intracranial lesions (1). In: Sutton D. Textbook of Radiology and Imaging. Edinburg: Churchill-Livingstone; 2003. p. 1763.

4. Bhatoe HS, Mukherji JD, Dutta V. Epidermoid tumour of the lateral ventricle. Acta Neurochir 2006; 148: $339-42$.

5. Koot RW, Jagtap AP, Akkerman EM, Den Heeten GJ, Majoie CB. Epidermoid of the lateral ventricle: evaluation with diffusion-weighted and diffusion tensor imaging. Clin Neurol Neurosurg 2003; 105: 207-3.

6. Menq L, Yuqanq L, Shuqan Z, Xinqanq L, Chenqyuan W. Intraventricular epidermoids. J Clin Neurosci 2006; 13: 428-30.

7. Delfini R, Acqui M, Oppoido PA, Capone R, Santoro A, Ferrante L. Tumors of the lateral ventricles. Neurosurg Rev 1991; 14: 127-33.

8. Koeller KK, Sandberg GD. From the Archives of the AFIP: Cerebral intraventricular neoplasms: radiologic-pathologic correlation. Radiographics 2002; 22: 1473-505.

9. Imamura Y, Ninchaji T, Nakajima S, Uemura K. Epidermoid tumor in the fourth ventricle with particular reference to metrizamide CT cisternography findings. Surg Neurol 1982; 18: 444-7.

10. Panagopoulos KP, el-Azouzi M, Chisholm HL, Jolesz FA, Black PM. Intracranial epidermoid tumors. A continuing diagnostic challenge. Arch Neurol 1990; 47: 813-6. 